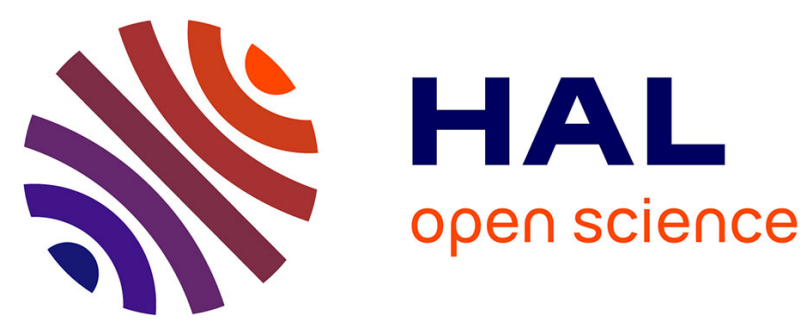

\title{
MISSENSE MUTATIONS IN THE AFG3L2 PROTEOLYTIC DOMAIN ACCOUNT FOR $1.5 \%$ OF EUROPEAN AUTOSOMAL DOMINANT CEREBELLAR ATAXIAS
}

Claudia Cagnoli, Giovanni Stevanin, Alessandro Brussino, Cecilia Mancini, Russell Margolis, Susan Holmes, Marcello Nobili, Sylvie Forlani, Sergio Padovan, Patrizia Pappi, et al.

\section{- To cite this version:}

Claudia Cagnoli, Giovanni Stevanin, Alessandro Brussino, Cecilia Mancini, Russell Margolis, et al.. MISSENSE MUTATIONS IN THE AFG3L2 PROTEOLYTIC DOMAIN ACCOUNT FOR $1.5 \%$ OF EUROPEAN AUTOSOMAL DOMINANT CEREBELLAR ATAXIAS. Human Mutation, 2010, 31 (10), pp.1117. 10.1002/humu.21342 . hal-00574001

\section{HAL Id: hal-00574001 https://hal.science/hal-00574001}

Submitted on 7 Mar 2011

HAL is a multi-disciplinary open access archive for the deposit and dissemination of scientific research documents, whether they are published or not. The documents may come from teaching and research institutions in France or abroad, or from public or private research centers.
L'archive ouverte pluridisciplinaire HAL, est destinée au dépôt et à la diffusion de documents scientifiques de niveau recherche, publiés ou non, émanant des établissements d'enseignement et de recherche français ou étrangers, des laboratoires publics ou privés. 


\section{Human Mutation}

WILEY

\section{MISSENSE MUTATIONS IN THE AFG3L2 PROTEOLYTIC DOMAIN ACCOUNT FOR 1.5\% OF EUROPEAN AUTOSOMAL DOMINANT CEREBELLAR ATAXIAS}

\begin{tabular}{|c|c|}
\hline Journal: & Human Mutation \\
\hline Manuscript ID: & humu-2010-0123.R1 \\
\hline Wiley - Manuscript type: & Rapid Communication \\
\hline $\begin{array}{r}\text { Date Submitted by the } \\
\text { Author: }\end{array}$ & $15-J u l-2010$ \\
\hline Complete List of Authors: & $\begin{array}{l}\text { Cagnoli, Claudia; University of Turin, Genetics Biology and } \\
\text { Biochemistry } \\
\text { Stevanin, Giovanni; INSERM/UPMC UMR_S975 } \\
\text { Brussino, Alessandro; University of Turin, Genetics Biology and } \\
\text { Biochemistry } \\
\text { Mancini, Cecilia; University of Turin, Genetics Biology and } \\
\text { Biochemistry } \\
\text { Margolis, Russell; Johns Hopkins University School of Medicine } \\
\text { Holmes, Susan; Johns Hopkins University School of Medicine } \\
\text { Nobili, Marcello; Division of Neurology, Martini Hospital } \\
\text { Forlani, Sylvie; INSERM/UPMC UMR_S975 } \\
\text { Padovan, Sergio; cnr } \\
\text { Pappi, Patrizia; University of Turin, Genetics Biology and } \\
\text { Biochemistry } \\
\text { Zaros, Cecile; INSERM/UPMC UMR_S975 } \\
\text { Le Ber, Isabelle; INSERM/UPMC UMR_S975 } \\
\text { Ribai, Pascale; INSERM/UPMC UMR_S975 } \\
\text { Pugliese, Luisa; SAFAN bioinformatics } \\
\text { assalto, corrado; SAFAN bioinformatics } \\
\text { Brice, Alexis; INSERM U679, Hôpital de la Salpêtrière } \\
\text { Migone, Nicola; University of Turin, Genetics Biology and } \\
\text { Biochemistry } \\
\text { Durr, Alexandra; INSERM U679, Hôpital de la Salpêtrière } \\
\text { Brusco, Alfredo; University of Turin, Department of Genetics } \\
\text { Biology and Biochemistry }\end{array}$ \\
\hline Key Words: & $\begin{array}{l}\text { Autosomal Dominant Cerebellar Ataxia, Spinocerebellar ataxia, } \\
\text { SCA28, AFG3L2, mutation screening }\end{array}$ \\
\hline
\end{tabular}




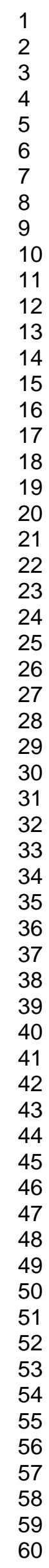

\section{SCHOLARONE ${ }^{m}$ Manuscripts}

7

8

10

11

13

14

15

16

18

19

20

22

23

25

26

28

30

31

33

34

35

36

38

39

40

41

43

44

45

46

47

48

50

51

52

54

55

58

59

60

John Wiley \& Sons, Inc. 


\section{MISSENSE MUTATIONS IN THE AFG3L2 PROTEOLYTIC DOMAIN ACCOUNT FOR 1.5\% OF EUROPEAN AUTOSOMAL DOMINANT CEREBELLAR ATAXIAS}

Claudia Cagnoli, ${ }^{1,2}$ Giovanni Stevanin, ${ }^{3,4,5,10}$ Alessandro Brussino, ${ }^{1,2}$ Marco Barberis, ${ }^{1,2}$ Cecilia Mancini, ${ }^{1,2}$ Russell L.Margolis, ${ }^{6}$ Susan E.Holmes, ${ }^{6}$ Marcello Nobili, ${ }^{7}$ Sylvie Forlani, ${ }^{3,5}$ Sergio Padovan, ${ }^{8}$ Patrizia Pappi, ${ }^{2}$ Cécile Zaros, ${ }^{5}$ Isabelle Leber, ${ }^{3,5}$ Pascale Ribai, ${ }^{3,4}$ Luisa Pugliese, ${ }^{9}$ Corrado Assalto, ${ }^{9}$ Alexis Brice, ${ }^{3,45}$ Nicola Migone, ${ }^{1,2}$ Alexandra Dürr, ${ }^{3,4,5}$ and Alfredo Brusco ${ }^{1,2}$

${ }^{1}$ Department of Genetics, Biology and Biochemistry, University of Torino

${ }^{2}$ S.C. Medical Genetics, A.O.U. San Giovanni Battista, Torino, Italy

${ }^{3}$ INSERM, U975 (formerly U679), Paris, France

${ }^{4}$ UPMC Univ. Paris 6, UMR_S975, Centre de Recherche de l'Institut du Cerveau et de la Moelle épinière, CNRS 7225, Pitié-Salpêtrière Hospital, 75013 Paris, France

${ }^{5}$ APHP, Pitié-Salpêtrière Hospital, Department of Genetics and Cytogenetics, Paris, France

${ }^{6}$ Department of Psychiatry and Behavioral Sciences, Johns Hopkins University School of Medicine, Baltimore, Maryland, USA

${ }^{7}$ Division of Neurology, Martini Hospital, Turin, Italy

${ }^{8}$ IBB-CNR c/o Molecular Biotecnology Center University of Torino, Via Nizza 52, I 10125 Torino, Italy

${ }^{9}$ S.A.F.AN. BIOINFORMATICS, Turin (Italy)

${ }^{10}$ Ecole Pratique des Hautes Etudes (EPHE), Paris, France

Correspondence to: Alfredo Brusco, Dipartimento di Genetica Biologia e Biochimica, Università degli Studi di Torino, via Santena 19, 10126, Torino, Italy. Fax +390112366662; e-mail: alfredo.brusco@unito.it

Running title: SCA28 mutations

Paper word count: 5391 
SCA28 Cagnoli C

\begin{abstract}
Spinocerebellar ataxia type 28 is an autosomal dominant form of cerebellar ataxia (ADCA) caused by mutations in $A F G 3 L 2$, a gene that encodes a subunit of the mitochondrial $m$-AAA protease. We screened 366 primarily Caucasian ADCA families, negative for the most common tripletexpansions, for point mutations in AFG3L2 using DHPLC. Whole-gene deletions were excluded in 300 of the patients, and duplications were excluded in 129 patients. We found six missense mutations in nine unrelated index cases (9/366, 2.6\%): c.1961C $>\mathrm{T}$ (p.Thr654Ile) in exon 15, c.1996A>G (p.Met666Val), c.1997T>G (p.Met666Arg), c.1997T>C (p.Met666Thr), c.2011G>A (p.Gly671Arg), and c.2012G>A (p.Gly671Glu) in exon 16. All mutated amino acids were located in the C-terminal proteolytic domain. In available cases, we demonstrated the mutations segregated with the disease. Mutated amino acids are highly conserved, and bioinformatic analysis indicates the substitutions are likely deleterious. This investigation demonstrates that SCA28 accounts for $\sim 3 \%$ of ADCA Caucasian cases negative for triplet expansions and, in extenso, to $\sim 1.5 \%$ of all ADCA. We further confirm both the involvement of AFG3L2 gene in SCA28 and the presence of a mutational hotspot in exons 15-16. Screening for SCA28, is warranted in patients who test negative for more common SCAs and present with a slowly progressive cerebellar ataxia accompanied by oculomotor signs.
\end{abstract}

Key Words: Autosomal Dominant Cerebellar Ataxia; Spinocerebellar ataxia; SCA28; AFG3L2; mutation screening 
SCA28 Cagnoli C

\section{INTRODUCTION}

Autosomal dominant cerebellar ataxias (ADCAs, or SCAs) are a group of clinically heterogeneous neurodegenerative disorders primarily characterized by imbalance, progressive gait and limb ataxia, and dysarthria (Harding, 1993). The clinical phenotype is often complicated by the presence of additional neurological signs, which are highly variable among and within families (Finsterer, 2009; Schols, et al., 2004). SCAs are among the most genetically heterogeneous neurodegenerative diseases, at present nearly thirty genetically distinct subtypes have been defined (http://www.neuro.wustl.edu/neuromuscular/ataxia/domatax.html). In most countries, an expansion of a coding CAG-triplet repeat, resulting in production of a protein with an abnormal polyglutamine (polyQ) stretch, accounts for 40-60\% of ADCA. In some populations, as in Southern Brazil, founder effects have raised this ratio up to $\sim 100 \%$ (Jardim, et al., 2001; Storey, et al., 2000). Less common SCAs are caused by other types of mutations: the expansion of a tri- or penta-nucleotide in untranslated regions (CAG in SCA12, ATTCT in SCA10, and TGGAA in SCA31), by point mutations (SCA5, SCA11, SCA13, SCA14, and SCA27), or by gene dosage anomalies (SCA15 and SCA20) (Fahey, et al., 2005; Holmes, et al., 1999; Houlden, et al., 2007; Ikeda, et al., 2006; Knight, et al., 2008; Matsuura and Ashizawa, 2002; Sato, et al., 2009; van de Leemput, et al., 2007; Waters, et al., 2006). Most recently, point mutations of AFG3L2 (OMIM \#610246) have been shown to cause SCA28 (Di Bella, et al., 2010; Edener, et al., 2010). AFG3L2 was originally cloned as a paralogue of the SPG7 gene (encoding for paraplegin, OMIM *602783) (Banfi, et al., 1999), whose loss-of-function causes an autosomal recessive form of hereditary spastic paraplegia (HSP) (Casari, et al., 1998). AFG3L2 encodes for a subunit of the hetero-oligomeric $m$-AAA protease (ATPases associated with various cellular activities), a component of the mitochondrial ATP-dependent metalloprotease located on the inner mitochondrial membrane. The AAA metalloproteases take part in proteolytic quality control and chaperon-like activities in mitochondria by degrading misfolded proteins and promoting the assembly of respiratory chain complexes (Leonhard, et al., 1999). Here we examine the prevalence of SCA28 among Caucasian ADCA families, further defining the 
SCA28 Cagnoli C

scope and pathogenicity of $A F G 3 L 2$ mutations and the clinical features of this disease.

\section{PATIENTS AND METHODS}

\section{Patients}

We recruited 366 index cases with progressive cerebellar ataxia and a family history of a similar disorder (defined as the presence of at least two affected individuals in at least two consecutive generations). The mean age at onset was $41.1 \pm 18.3$ years (range: $1-79$ years; onset defined as the year of the first symptoms, as reported by the patient or the family). When possible, additional family members were recruited if a mutation in $A F G 3 L 2$ was found in a proband. Most patients originated from France $(n=240)$, but the collection also included patients from other countries in Europe $(n=50)$, the United States ( $n=66$, predominately of European origin), North-Africa/MiddleEast $(n=6)$, French West-Indies $(n=3)$ and Madagascar $(n=1)$. We excluded individuals with pathogenic expansions in the SCA1-3, 6, 7, 17 and DRPLA loci, or recurrent mutations in the SCA5, SCA13, SCA14, or FGF14/SCA27 loci (Klebe, et al., 2005) (Stevanin et al., unpublished data). Clinical and genetic studies were performed after obtaining informed consent from all participants or the parents of participating minors and with the approval of the local ethics committees. Ninety-five French and 95 Italian healthy controls were examined to establish the frequency of variants in the normal population.

\section{Mutation screening}

The 17 coding exons of the AFG3L2 gene (RefSeq NM_006796.1) were PCR amplified using primer and conditions reported in Supp. materials and methods and Supp. Table S1. Mutation analysis was performed on the amplicons using a DHPLC WAVE System (Transgenomics) with melting temperatures $\left(\mathrm{Tm}\right.$ and $\left.\mathrm{Tm}+2^{\circ} \mathrm{C}\right)$ determined by DHPLC Melt software (Jones, et al., 1999) (Supp. Table S1). A normal control profile was always compared with that from a patient. PCR products showing a DHPLC peak shift were purified using the ExoSAP method (MBI-Fermentas, 
Vilnius, Lithuania), and directly sequenced using the Big-Dye terminator cycle sequencing kit ver. 1.1 and an ABI Prism 3100 Avant automatic sequencer (Applied Biosystems, Foster City, CA). The 17 coding exons of the SPG7 gene (RefSeq NM_003119.2) were also amplified and directly sequenced following primers and conditions reported in Supp. materials and methods and Supp. Table S2.

AFG3L2 gene copy number was evaluated by quantitative duplex PCR (qPCR) using a Roche-UPL assay centered on exon 14 (Roche-Diagnostics, Mannheim, Germany). The gene dosage strategy was based on the relative amplification of the target sequence (AFG3L2) and the co-amplified internal standard RNaseP using the comparative delta $\mathrm{Ct}$ method described elsewhere (Livak and Schmittgen, 2001) (see Supp. materials and methods).

Nucleotide numbering throughout the paper follows cDNA numbering: +1 refers to the first nucleotide of the ATG translation initiation codon of the corresponding RefSeq, according to journal guidelines (www.hgvs.org/mutnomen). The initiation codon is codon 1.

\section{Haplotype reconstruction}

Five 6-FAM fluorescently-labelled microsatellites spanning $\sim 10 \mathrm{Mb}$ on chromosome 18 , including two markers telomeric (D18S1150 and D18S53) and three centromeric (D18453,D18S1104, and D18S1107) to $A F G 3 L 2$ were genotyped in all available subjects with a specific mutation whenever the mutation occurred in at least two unrelated families. We used standard PCR conditions and primers described at www.genome.ucsc.edu. Haplotypes were manually reconstructed.

\section{Homology modeling of AFG3L2, in-silico}

The three-dimensional model of human AFG3L2 protein was generated using "homology modelling", a bioinformatics algorithm that builds a model of the "target" protein based on the homology of its amino acid sequence with that of proteins of known structure (Marti-Renom, et al., 2000). The AFG3L2 protein model was constructed with the NEST application (Petrey, et al., 
SCA28 Cagnoli C

2003), using the T. maritima FtsH 2CE7 crystal structure as a template (see Supp. materials and methods). Mutations p.Thr654Ile, p.Met666Val, p.Met666Thr, p.Met666Arg, p.Gly671Glu and p.Gly671Arg were introduced into the model with the Yasara software (http://www.yasara.org) and their consequences were evaluated using a series of bioinformatics tools (see also Supp. materials and methods).

Multiple species alignment of AFG3L2 protein was made with the ClustalW software (http://www.ebi.ac.uk/Tools/clustalw2/index.html) using orthologue sequences obtained through the Ensembl genome browser (http://www.ensembl.org). In silico analysis of the possible pathogenicity of each amino acid substitution was performed with two different applications: (i) PolyPhen (“Polymorphism Phenotyping”, http://genetics.bwh.harvard.edu/pph/index.html), selecting the Protein Data-Base (PDB) as a source for sequence alignment, and (ii) SIFT ("Sorting Intolerant From Tolerant", http://blocks.fhcrc.org/sift/). Possible effects on splicing were checked using the applications Splice Site Prediction (http://www.fruitfly.org/seq_tools/splice.html) (Reese, et al., 1997), ESEfinder 2.0 (http://rulai.cshl.edu/tools/ESE/) (Cartegni, et al., 2003; Smith, et al., 2006), and PESXs (http://cubweb.biology.columbia.edu/pesx/) (Zhang, et al., 2005). One variant, predicted to alter splicing, was further investigated using a minigene assay (see Supp. materials and methods).

\section{RESULTS}

SCA28 mutations in ADCA families.

Three-hundred sixty six unrelated patients with ADCA were screened for point mutations in the AFG3L2 gene using DHPLC, followed by direct sequencing of the amplimers with shifted peaks. We found six missense changes in nine unrelated index cases: eight were French and one was of Italian origin (9/366, 2.6\%): c.1961C>T (p.Thr654Ile) in exon 15, c.1996A>G (p.Met666Val), c.1997T>G (p.Met666Arg), c.1997T>C (p.Met666Thr), c.2011G>A (p.Gly671Arg) and c.2012G>A (p.Gly671Glu) in exon 16 (Figure 1). These mutations were not reported as 
SCA28 Cagnoli C

polymorphisms in the dbSNP database build 130 (http://www.ncbi.nlm.nih.gov/projects/SNP/), and were not found among 380 French or Italian healthy control chromosomes. DNA from 27 additional family members in six families was available, which allowed us to verify that the mutation segregated with the disease and was absent in healthy relatives (Figure 2). The mutations were located in the peptidase-M41 domain of the AFG3L2 protein. Multiple species alignment showed that the three amino acids altered by mutations (Thr654, Met666 and Gly671) are conserved through Saccharomyces cerevisiae (Figure 1). The applications PolyPhen and SIFT predicted that all the amino acid mutations are deleterious. Three mutations (p.Thr654Ile, p.Met666Val and p.Gly671Arg) were found in two families each. Haplotype reconstruction showed that identical mutations shared a common haplotype, suggesting that the families have a common ancestor (Figure 2).

In addition to the six missense mutations, we found 25 variants, 14 of which were neither reported as polymorphisms in the dbSNP database nor found in healthy controls (Supp. Table S3). Twelve were intronic nucleotide changes and two were synonymous substitutions. In silico analysis of the effect of each variant on splicing showed that c.293-13_293-14delTT changes the score of the exon 4 acceptor splice site from 0.22 to 0.03 . Neither relatives nor cDNA of this patient were available for further study. We tested the effect of this mutation using a minigene assay, which showed it has no effect on splicing.

We also excluded whole-gene deletion/duplication of $A F G 3 L 2$ in 129/366 subjects (35\%) by qPCR of exon 14, and deletions in 171 patients, who carried one or more heterozygous SNP at DHPLC and / or direct sequencing.

$3 D$ reconstruction of $A F G 3 L 2$ and predicted effect of the mutations on intermolecular electrostatic parameters.

The three-dimensional reconstruction of the C-terminal region of AFG3L2, the homohexameric complex, and the relative positions of mutated amino acids are depicted in Figure 3A-B. Based on 
SCA28 Cagnoli C

this model, the amino acids Met666 and Gly671 are always on the surface of the complex, regardless of the conformation analyzed, suggesting that these two residues may be involved in interactions with other molecules. p.Gly671Glu significantly increases the electrostatic potential difference between the inner-mitochondrial-membrane side and the matrix side of the hexamer, whereas p.Met666Arg and p.Gly671Arg decreased it (Figure 3C and Supp. Table S4). The other three mutations do not significantly affect the potential difference (Supp. Table S4). Given that the central pore of the m-AAA complex (Figure 3D) is used to convey substrates to the proteolytic chamber (Kress and Weber-Ban, 2009), we investigated the effect of the mutations of the amino acids close to the central pore. As shown in Figure 3E, 3F and Supp. Table S4, p.Gly671Glu increases the central pore dipole energy, and p.Met666Arg and p.Gly671Arg decreased it. In addition, we found that all the mutations analyzed decreases the mean interaction energy of the hexamer, destabilizing the m-AAA complex (Supp. Table S5). Taken together, the bioinformatics data point to a generalized destabilizing effect of the six mutations detected in our patient population, with p.Met666Arg, p.Gly671Glu, and p.Gly671Arg also affecting the charge of the hexamer and, in particular, the charge of the translocation channel.

\section{SPG7 mutation analysis}

Since AFG3L2 and paraplegin can interact to form the multimeric $m$-AAA protease complex, we speculated that $S P G 7$ variants could modify the SCA28 phenotype. We screened for $S P G 7$ variants by direct sequencing the coding exons of nine SCA28 patients with the earliest onset (AAD-080_9, AAR-197_1, SAL-872_6, SAL-872_9, SAL-331_11, AAD-444_3, AAD-444_9, AAD-455_19, AAD-701_21). Two unreported intronic variants were detected: c.1678+13 C >T in subject 701_21; c.2196+18 C>G in subject 331_11. Neither variant is predicted to alter splicing.

\section{Clinical features}

Table 1 reports the clinical and neuroradiological features of twenty-five SCA28 patients from ten 
families, 14 males and 11 females, clinically examined at a mean age of $45.4 \pm 17.7$ years (range 10-77 yrs). The mean age at onset was $30.7 \pm 16.2$ yrs (range: 6-60 yrs). Cerebellar gait ataxia was the initial clinical abnormality in all but one patient (AAR-197_8). At examination, cerebellar ataxia was associated with dysarthria $(17 / 25,68 \%)$, ophthalmoplegia $(12 / 25,48 \%)$ and/or gazedevoked nystagmus (13/24, 54\%). In addition, saccadic pursuit was noted in 6/16 (37\%) and slow saccades were present in 3/12 (25\%). Ptosis was often present $(8 / 19,42 \%)$ and it was not correlated with disease duration $(\mathrm{p}=0.937)$. Summing up gazed-evoked nystagmus, ophthalmoplegia and ptosis, 19 out of 25 patients had one or more oculomotor anomalies (76\%). Six patients had a full pyramidal syndrome (i.e., increased reflexes and Babinski sign) and gait spasticity was evident in one patient (AAR-197_10), two features already described in SCA28 (Mariotti, et al., 2008). Interestingly, extrapyramidal signs, either dystonia $(n=3)$ or parkinsonism $(n=3)$, were also present although relatively infrequent (24\%). In patient SAL-872_6, the etiology of parkinsonism may have been related to concomitant treatment with a neuroleptic. Vibration sense at the ankles was decreased in $9 / 20$ patients (45\%), but nerve conduction studies, available for seven patients (five of whom had vibration sense alterations) were normal, with neurogenic changes on electromyography observed only in SAL-331_4 and SAL-331_11. Two patients from the same family (SAL-331) had low verbal IQ (78 and 89, respectively). Cerebral MRI $(n=10)$ or CT scan $(n=2)$ revealed cerebellar atrophy affecting predominantly the vermis. The brainstem was normal. A muscle biopsy performed in one patient was unremarkable.

Overall, the disease was slowly progressive and rarely severe. Only patient SAL-444_3 needed help for walking, 29 years after the onset of symptoms, and five clinically affected patients of two families were not functionally incapacitated (SAL-701_29, SAL-701_021, AAD-080_56, AAD080_57 and AAD-080_58).

\section{DISCUSSION}

The m-AAA protease is an ATP-dependent proteolytic complex located in the matrix side of the John Wiley 9 \& Sons, Inc. 
SCA28 Cagnoli C

inner mitochondrial membrane and involved, in yeast, in protein quality control and protein processing (Arlt, et al., 1996; Esser, et al., 2002; Leonhard, et al., 2000). Human m-AAA protease consists of two isoenzymes: (i) a hetero-oligomeric complex formed by paraplegin (SPG7) and AFG3L2, and (ii) a homo-oligomeric AFG3L2 complex. Loss-of-function mutations in the SPG7 gene cause an autosomal recessive hereditary spastic paraparesis (HSP), whereas AFG3L2 mutations cause SCA28 (Di Bella, et al., 2010; Edener, et al., 2010). In 366 unrelated ADCA patients of predominately European ancestry, we found nine affected subjects harboring six different AFG3L2 mutations, clustered in exons 15 (p.Thr654Ile) and 16 (p.Met666Arg, p.Met666Thr, p.Met666Val, p.Gly671Arg and p.Gly671Gln). The pathogenicity of these missense substitutions is supported by multiple lines of evidence: (i) in families where more than one affected subject was available, we demonstrated that the mutation segregated with the disease and was not present in healthy subjects of the family. In one of these families (AAD-080), a positive multipoint LOD score of 2.54 at D18S853 highly suggested its linkage to the SCA28 locus (data not shown). Moreover, STR-analysis revealed that patients from different families harboring the same mutation shared a common haplotype, suggesting the presence of common ancestors. (ii) Mutations were not found in 380 control chromosomes. (iii) The mutated amino acids are evolutionary conserved up to the S. cerevisiae orthologous protein Yta10, and all are located in the M41-proteolytic domain of the protein. (iv) Bioinformatic analysis of the protein showed that the mutations alter the interaction of each monomer with the other five, symptomatic of an altered stability of the complex. Yeast complementation studies, beyond the scope of this investigation, would further establish the functional significance of these mutations.

The $m$-AAA mechanism of action is still under study, although recent investigations of its bacterial homologue FtsH indicate that the protease ring is stationary and that coordinated ATP-driven movements of each monomer accomplish substrate unfolding and translocation to the proteolytic chamber (Augustin, et al., 2009; Bieniossek, et al., 2009). The electrostatic potential difference of the complex and the dipole of the central pore are altered in three of the six mutations that we 
detected. Furthermore, all six mutations diminish the interaction energy among monomers. These effects of the mutations suggest that each may have a negative effect on the $m$-AAA complex activity. For instance, the capacity of the complex to move substrates towards the proteolytic chamber through ATPase activity may be impaired by weaker interaction among monomers or by abnormal electrostatic potentials through the central pore (Striebel, et al., 2009).

Five of the six $A F G 3 L 2$ missense mutations previously reported, cluster in the proteolytic domain at amino acids Ser674, Glu691, Ala694, Glu700, and Arg702 (exon 16) (Di Bella, et al., 2010; Edener, et al., 2010). We found different mutations affecting the same amino acids (p.Gly671Arg and p.Gly671Glu; p.Met666Arg, p.Met666Thr, and p.Met666Val) indicating that exons 15 and 16 are mutational hotspots for SCA28, and consistent with the hypothesis that disruption of the peptidase domain is critical to the pathogenesis of SCA28.

Recent evidences from animal models also support the pathogenicity of AFG3L2 mutations: Afg $3 l 2$ knock-out mice presents with a severe neuromuscular phenotype, caused by a defect in motor axon and cerebellar development (Maltecca, et al., 2008), whereas the $A f g 3 l 2^{\text {Emv66 }}$ mouse, carrying a heterozygous loss-of-function mutation, develops a phenotype with similarities to SCA28 (Maltecca, et al., 2009). Whole gene deletions were excluded in 300/366 patients and duplications in 129/366, suggesting that AFG3L2 deletions/duplications are not common in ADCAs. Moreover, two related patients with an $18 \mathrm{p}$ deletion encompassing $A F G 3 L 2$ reportedly have not developed ataxia (Nasir, et al., 2006). Copy number variants encompassing part or whole of $A F G 3 L 2$ gene exist in normal individuals (Kim, et al., 2009; Redon, et al., 2006). Therefore, in addition to the results of our screening designed to detect only large deletions and duplications, the absence of a phenotype in humans with duplications and deletions affecting $A F G 3 L 2$, and the different phenotype observed in Afg $3 l 2$ null mice compared to $A f g 3 l 2^{\text {Emv66 }}$ mice, suggest that heterozygous deletions or duplications of the AFG3L2 gene may not cause SCA28. Looking at rearrangements in SCA28 should therefore not be prescribed in clinical practice.

Our survey shows that SCA28 is rare among European ADCA patients, accounting for $\sim 3 \%$ of the John Wiley 11 Sons, Inc. 
SCA28 Cagnoli C

analyzed cases and $\sim 1.5 \%$ of all ADCAs. As a comparison, polyglutamine expansions account for about 50\%. The clinical and neuroradiological phenotype of the newly ascertained families is similar to that of the SCA28 patients reported so far (Cagnoli, et al., 2006; Edener, et al., 2010; Mariotti, et al., 2008): disease onset is in adulthood and the disease progresses slowly with preserved functional capacity, decades after the diagnosis. The mean age at onset and age at onset variability is similar in our series and in the reported families: in five patients the onset was above 50 yrs, whereas two subjects were symptomatic at 6 and 8 yrs. Even in the young onset cases, the disease progressed relatively slowly, a much different pattern than has been observed in the polyglutamine diseases and evidence that SCA28 is not caused by cryptic polyglutamine expansion. Interestingly, extrapyramidal features were not rare in our series of patients in contrast to previous reports, of potential value in speculating on the clinical diagnosis prior to genetic testing. As in many genetic diseases, particularly in those affecting the nervous system, the extent to which environmental factors affect disease phenotype, including onset age, selective neuronal involvement, and disease progression, remains to be determined.

Given the signs and symptoms of the disease, we suggest that the diagnosis of SCA28 should be considered in the presence of slowly progressive ataxia associated with oculomotor abnormalities. So far, $A F G 3 L 2$ mutations seem to cluster in exons 10, 15, and 16, which should facilitate genetic diagnosis in clinical practice and a better understanding of the function and misfunction of AFG3L2.

\section{Acknowledgments.}

We are grateful to the family members for their participation, to the DNA and Cell bank of the Centre de Recherche de l'Institut du Cerveau et de la Moelle épinière for technical assistance and to Drs C Marelli, J Yaouang, M Ponsot, H Chneiweiss, D Ménard, S Schaeffer, A Lagueny, L Carluer and Y Boukhriche as well as Prof A Harding for referring some of the patients and for clinical examinations. 
SCA28 Cagnoli C

This work was funded by Telethon Research grant GGP07110 (to A Brusco), Regione Piemonte Ricerca Sanitaria Finalizzata, the European Union (to the EUROSCA consortium), the VERUM foundation (to A Brice) and the Programme Hospitalier de Recherche Clinique (to A Durr).

John Wiley 13 Sons, Inc. 
SCA28 Cagnoli C

\section{FIGURE LEGENDS}

Figure 1.

Localization of the six $A F G 3 L 2$ missense mutations. In the upper panel the amino acid alignment of the AFG3L2 protein corresponding to a region including a portion of exons 15 and 16 is shown for 13 orthologous proteins from $H$. sapiens to S. cerevisiae. The mutated amino acids Thr654, Met666 and Gly671 are highlighted. Below, a scheme of the AFG3L2 genomic region and the protein are shown. Domain names are: MTS: mitochondrial targeting signal; TM: transmembrane domain; FtsH: Filamentation temperature sensitive H proteolytic domain; AAA: ATPase Associated with different cellular activities.

Figure 2.

Pedigrees of the nine families segregating a $A F G 3 L 2$ mutation. Square and circles shadings: white = healthy; black = SCA28; gray $=$ presumed SCA28; hash $=$ asymptomatic subject carrying a disease haplotype. Five STR markers (on the left) were used to reconstruct the SCA28-surrounding haplotype that suggest a common ancestor for p.Thr541Ile, p.Met666Val and p.Gly671Arg mutations, in two families each. All subjects whose DNA was available (hyphen above the symbol) were tested for the $A F G 3 L 2$ mutation segregating in the family.

Figure 3.

Bioinformatics analysis of AFG3L2 missense changes. Panel A, monomeric structure of the AFG3L2 protein, with the localization of ATP (yellow), the $\mathrm{Zn}^{++}$ion (pink) and the three mutated amino acids, Thr541 (light blue), Met666 (dark blue) and Gly671 (green). Panel B, matrix-side view of AFG3L2 hexamer (see panel A for color-code of $\mathrm{Zn}^{++}$and mutated amino acids); a dotted line shows the cross-section level of panel C. Panel C, electrostatic potential at the surface of the AFG3L2 hexamer viewed from the matrix side (upper row) and from the IMM side (lower row) is 
SCA28 Cagnoli C

reported for the mutations changing the potential difference. The mutation analyzed is reported between the images of the two surfaces; blue = positive charges, red = negative charges; the black box identifies the central pore magnified in panels $\mathrm{E}$ (membrane side) and $\mathrm{F}$ (matrix side). In panels $\mathrm{E}$ and $\mathrm{F}$ only the charges of the amino acids closer than $10 \AA$ from the geometric center of the dipole are shown. Panel D, side-view of the hexamer with the localization of the central translocation channel colored $($ blue $=$ positive charges, red = negative charges $) ; \mathrm{wt}=$ wild-type; $\mathrm{IMM}=$ inner mitochondrial membrane. 


\section{REFERENCES}

Arlt H, Tauer R, Feldmann H, Neupert W, Langer T. 1996. The YTA10-12 complex, an AAA protease with chaperone-like activity in the inner membrane of mitochondria. Cell 85(6):875-85.

Atorino L, Silvestri L, Koppen M, Cassina L, Ballabio A, Marconi R, Langer T, Casari G. 2003. Loss of m-AAA protease in mitochondria causes complex I deficiency and increased sensitivity to oxidative stress in hereditary spastic paraplegia. J Cell Biol 163(4):777-87.

Augustin S, Gerdes F, Lee S, Tsai FT, Langer T, Tatsuta T. 2009. An intersubunit signaling network coordinates ATP hydrolysis by m-AAA proteases. Mol Cell 35(5):574-85.

Banfi S, Bassi MT, Andolfi G, Marchitiello A, Zanotta S, Ballabio A, Casari G, Franco B. 1999. Identification and characterization of AFG3L2, a novel paraplegin-related gene. Genomics 59(1):51-8.

Bieniossek C, Niederhauser B, Baumann UM. 2009. The crystal structure of apo-FtsH reveals domain movements necessary for substrate unfolding and translocation. Proc Natl Acad Sci U S A 106(51):21579-84.

Cagnoli C, Mariotti C, Taroni F, Seri M, Brussino A, Michielotto C, Grisoli M, Di Bella D, Migone N, Gellera C and others. 2006. SCA28, a novel form of autosomal dominant cerebellar ataxia on chromosome 18p11.22-q11.2. Brain 129(Pt 1):235-42.

Cartegni L, Wang J, Zhu Z, Zhang MQ, Krainer AR. 2003. ESEfinder: A web resource to identify exonic splicing enhancers. Nucleic Acids Res 31(13):3568-71.

Casari G, De Fusco M, Ciarmatori S, Zeviani M, Mora M, Fernandez P, De Michele G, Filla A, Cocozza S, Marconi R and others. 1998. Spastic paraplegia and OXPHOS impairment caused by mutations in paraplegin, a nuclear-encoded mitochondrial metalloprotease. Cell 93(6):973-83.

Di Bella D, Lazzaro F, Brusco A, Plumari M, Battaglia G, Pastore A, Finardi A, Cagnoli C, Tempia F, Frontali M and others. 2010. Mutations in the mitochondrial protease gene AFG3L2 cause dominant hereditary ataxia SCA28. Nat Genet 42(4).

Edener U, Wollner J, Hehr U, Kohl Z, Schilling S, Kreuz F, Bauer P, Bernard V, GillessenKaesbach G, Zuhlke C. 2010. Early onset and slow progression of SCA28, a rare dominant ataxia in a large four-generation family with a novel AFG3L2 mutation. Eur J Hum Genet.

Esser K, Tursun B, Ingenhoven M, Michaelis G, Pratje E. 2002. A novel two-step mechanism for removal of a mitochondrial signal sequence involves the mAAA complex and the putative rhomboid protease Pcp1. J Mol Biol 323(5):835-43.

Fahey MC, Knight MA, Shaw JH, Gardner RJ, du Sart D, Lockhart PJ, Delatycki MB, Gates PC, Storey E. 2005. Spinocerebellar ataxia type 14: study of a family with an exon 5 mutation in the PRKCG gene. J Neurol Neurosurg Psychiatry 76(12):1720-2.

Finsterer J. 2009. Ataxias with autosomal, X-chromosomal or maternal inheritance. Can J Neurol Sci 36(4):409-28.

Gilis D, Rooman M. 2000. PoPMuSiC, an algorithm for predicting protein mutant stability changes: application to prion proteins. Protein Eng 13(12):849-56.

Guerois R, Nielsen JE, Serrano L. 2002. Predicting changes in the stability of proteins and protein complexes: a study of more than 1000 mutations. J Mol Biol 320(2):369-87.

Harding AE. 1993. Clinical features and classification of inherited ataxias. New York: Raven Press. Holmes SE, O'Hearn EE, McInnis MG, Gorelick-Feldman DA, Kleiderlein JJ, Callahan C, Kwak NG, Ingersoll-Ashworth RG, Sherr M, Sumner AJ and others. 1999. Expansion of a novel CAG trinucleotide repeat in the 5' region of PPP2R2B is associated with SCA12. Nat Genet 23(4):391-2.

Houlden H, Johnson J, Gardner-Thorpe C, Lashley T, Hernandez D, Worth P, Singleton AB, Hilton DA, Holton J, Revesz T and others. 2007. Mutations in TTBK2, encoding a kinase 
implicated in tau phosphorylation, segregate with spinocerebellar ataxia type 11 . Nat Genet 39(12):1434-6.

Ikeda Y, Dick KA, Weatherspoon MR, Gincel D, Armbrust KR, Dalton JC, Stevanin G, Durr A, Zuhlke C, Burk K and others. 2006. Spectrin mutations cause spinocerebellar ataxia type 5. Nat Genet 38(2):184-90.

Jardim LB, Silveira I, Pereira ML, Ferro A, Alonso I, do Ceu Moreira M, Mendonca P, Ferreirinha F, Sequeiros J, Giugliani R. 2001. A survey of spinocerebellar ataxia in South Brazil - 66 new cases with Machado-Joseph disease, SCA7, SCA8, or unidentified disease-causing mutations. J Neurol 248(10):870-6.

Jones AC, Austin J, Hansen N, Hoogendoorn B, Oefner PJ, Cheadle JP, O'Donovan MC. 1999. Optimal temperature selection for mutation detection by denaturing HPLC and comparison to single-stranded conformation polymorphism and heteroduplex analysis. Clin Chem 45(8 Pt 1):1133-40.

Jung J, Lee B. 2000. Protein structure alignment using environmental profiles. Protein Eng 13(8):535-43.

Kim KY, Lee GY, Kim J, Jeung HC, Chung HC, Rha SY. 2009. Identification of significant regional genetic variations using continuous $\mathrm{CNV}$ values in aCGH data. Genomics 94(5):317-23.

Klebe S, Durr A, Rentschler A, Hahn-Barma V, Abele M, Bouslam N, Schols L, Jedynak P, Forlani S, Denis E and others. 2005. New mutations in protein kinase Cgamma associated with spinocerebellar ataxia type 14. Ann Neurol 58(5):720-9.

Knight MA, Hernandez D, Diede SJ, Dauwerse HG, Rafferty I, van de Leemput J, Forrest SM, Gardner RJ, Storey E, van Ommen GJ and others. 2008. A duplication at chromosome 11q12.2-11q12.3 is associated with spinocerebellar ataxia type 20. Hum Mol Genet 17(24):3847-53.

Kress W, Weber-Ban E. 2009. The alternating power stroke of a 6-cylinder AAA protease chaperone engine. Mol Cell 35(5):545-7.

Krieger E, Darden T, Nabuurs SB, Finkelstein A, Vriend G. 2004. Making optimal use of empirical energy functions: force-field parameterization in crystal space. Proteins 57(4):678-83.

Leonhard K, Guiard B, Pellecchia G, Tzagoloff A, Neupert W, Langer T. 2000. Membrane protein degradation by AAA proteases in mitochondria: extraction of substrates from either membrane surface. Mol Cell 5(4):629-38.

Leonhard K, Stiegler A, Neupert W, Langer T. 1999. Chaperone-like activity of the AAA domain of the yeast Yme1 AAA protease. Nature 398(6725):348-51.

Livak KJ, Schmittgen TD. 2001. Analysis of relative gene expression data using real-time quantitative PCR and the 2(-Delta Delta C(T)) Method. Methods 25(4):402-8.

Maltecca F, Aghaie A, Schroeder DG, Cassina L, Taylor BA, Phillips SJ, Malaguti M, Previtali S, Guenet JL, Quattrini A and others. 2008. The mitochondrial protease AFG3L2 is essential for axonal development. J Neurosci 28(11):2827-36.

Maltecca F, Magnoni R, Cerri F, Cox GA, Quattrini A, Casari G. 2009. Haploinsufficiency of AFG3L2, the gene responsible for spinocerebellar ataxia type 28, causes mitochondriamediated Purkinje cell dark degeneration. J Neurosci 29(29):9244-54.

Mariotti C, Brusco A, Di Bella D, Cagnoli C, Seri M, Gellera C, Di Donato S, Taroni F. 2008. Spinocerebellar ataxia type 28: a novel autosomal dominant cerebellar ataxia characterized by slow progression and ophthalmoparesis. Cerebellum 7(2):184-8.

Marti-Renom MA, Stuart AC, Fiser A, Sanchez R, Melo F, Sali A. 2000. Comparative protein structure modeling of genes and genomes. Annu Rev Biophys Biomol Struct 29:291-325.

Matsuura T, Ashizawa T. 2002. Spinocerebellar ataxia type 10: a disease caused by a large ATTCT repeat expansion. Adv Exp Med Biol 516:79-97.

Nasir J, Frima N, Pickard B, Malloy MP, Zhan L, Grunewald R. 2006. Unbalanced whole arm translocation resulting in loss of 18p in dystonia. Mov Disord 21(6):859-63. 
SCA28 Cagnoli C

Petrey D, Xiang Z, Tang CL, Xie L, Gimpelev M, Mitros T, Soto CS, Goldsmith-Fischman S, Kernytsky A, Schlessinger A and others. 2003. Using multiple structure alignments, fast model building, and energetic analysis in fold recognition and homology modeling. Proteins 53 Suppl 6:430-5.

Redon R, Ishikawa S, Fitch KR, Feuk L, Perry GH, Andrews TD, Fiegler H, Shapero MH, Carson $\mathrm{AR}$, Chen $\mathrm{W}$ and others. 2006. Global variation in copy number in the human genome. Nature 444(7118):444-54.

Reese MG, Eeckman FH, Kulp D, Haussler D. 1997. Improved splice site detection in Genie. J Comput Biol 4(3):311-23.

Sato N, Amino T, Kobayashi K, Asakawa S, Ishiguro T, Tsunemi T, Takahashi M, Matsuura T, Flanigan KM, Iwasaki S and others. 2009. Spinocerebellar ataxia type 31 is associated with "inserted" penta-nucleotide repeats containing (TGGAA)n. Am J Hum Genet 85(5):544-57.

Schols L, Bauer P, Schmidt T, Schulte T, Riess O. 2004. Autosomal dominant cerebellar ataxias: clinical features, genetics, and pathogenesis. Lancet Neurol 3(5):291-304.

Smith PJ, Zhang C, Wang J, Chew SL, Zhang MQ, Krainer AR. 2006. An increased specificity score matrix for the prediction of SF2/ASF-specific exonic splicing enhancers. Hum Mol Genet 15(16):2490-508.

Storey E, du Sart D, Shaw JH, Lorentzos P, Kelly L, McKinley Gardner RJ, Forrest SM, Biros I, Nicholson GA. 2000. Frequency of spinocerebellar ataxia types 1, 2, 3, 6, and 7 in Australian patients with spinocerebellar ataxia. Am J Med Genet 95(4):351-7.

Striebel F, Kress W, Weber-Ban E. 2009. Controlled destruction: AAA+ ATPases in protein degradation from bacteria to eukaryotes. Curr Opin Struct Biol 19(2):209-17.

van de Leemput J, Chandran J, Knight MA, Holtzclaw LA, Scholz S, Cookson MR, Houlden H, Gwinn-Hardy K, Fung HC, Lin X and others. 2007. Deletion at ITPR1 underlies ataxia in mice and spinocerebellar ataxia 15 in humans. PLoS Genet 3(6):e108.

Vriend G. 1990. WHAT IF: a molecular modeling and drug design program. J Mol Graph 8(1):52$6,29$.

Waters MF, Minassian NA, Stevanin G, Figueroa KP, Bannister JP, Nolte D, Mock AF, Evidente VG, Fee DB, Muller U and others. 2006. Mutations in voltage-gated potassium channel KCNC3 cause degenerative and developmental central nervous system phenotypes. Nat Genet 38(4):447-51.

Zhang XH, Kangsamaksin T, Chao MS, Banerjee JK, Chasin LA. 2005. Exon inclusion is dependent on predictable exonic splicing enhancers. Mol Cell Biol 25(16):7323-32. 


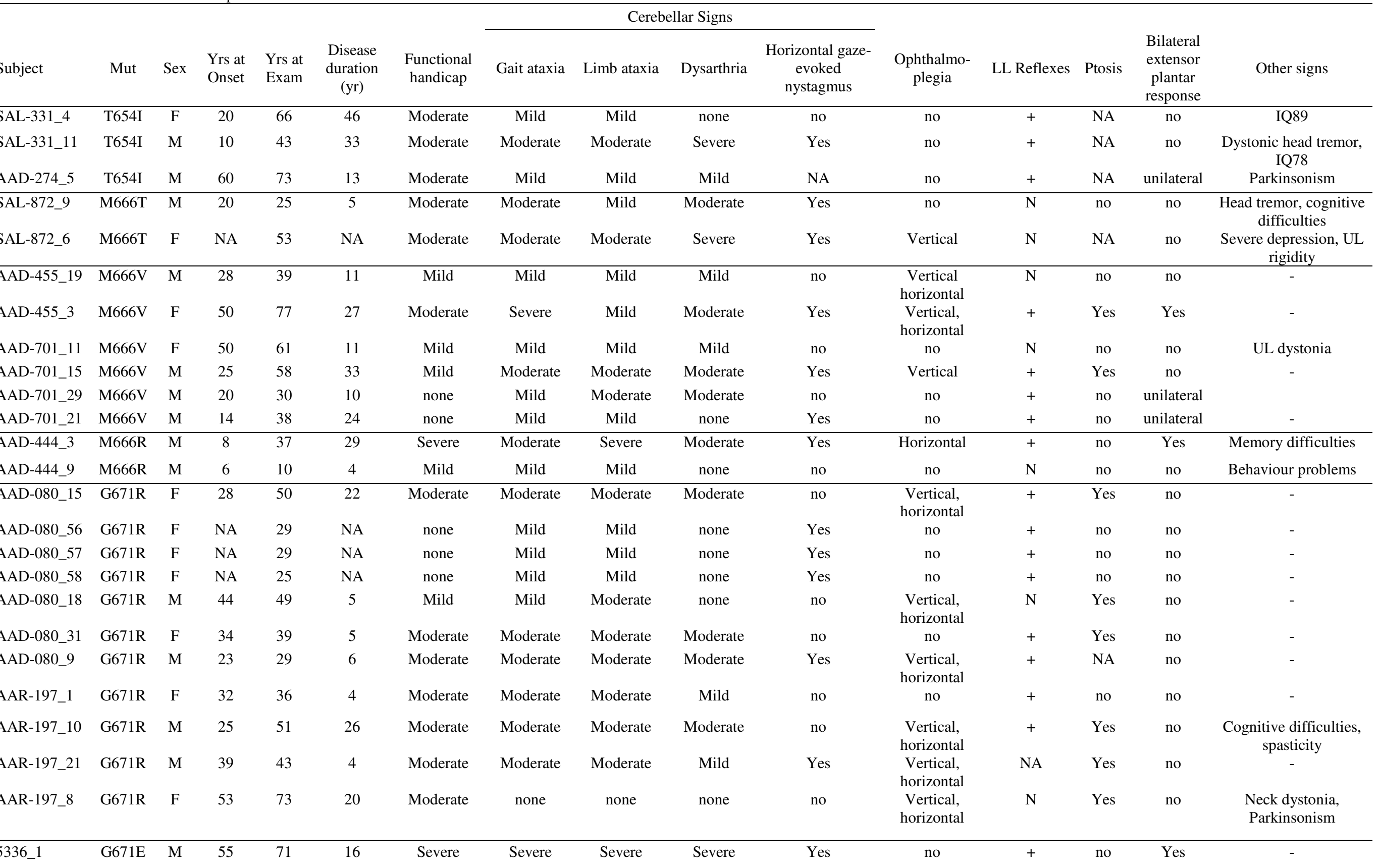

Notes: LL, lower limbs; UL, upper limbs; N, normal; +, augmented; NA, not available;

John Wiley \& Sons, Inc. 


\section{Page 21 of 30}

Figure 1

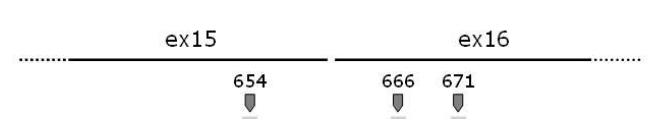



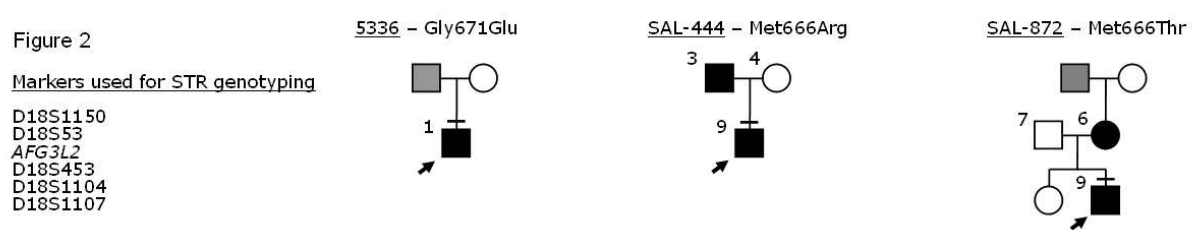

SAL-331 - Thr654Ile $\quad \underline{\text { AAD-274 - Thr654Ile }}$
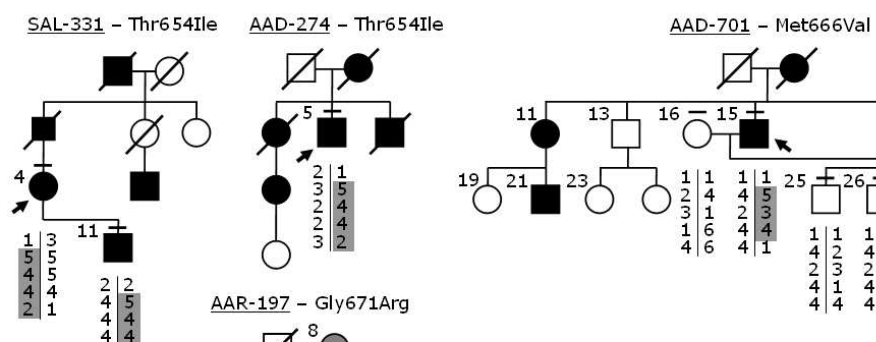

AAD-701 - Met666Val

AAD-455 - Met666Val

\section{$451 \times 361 \mathrm{~mm}(72 \times 72 \mathrm{DPI})$}

John Wiley \& Sons, Inc. 

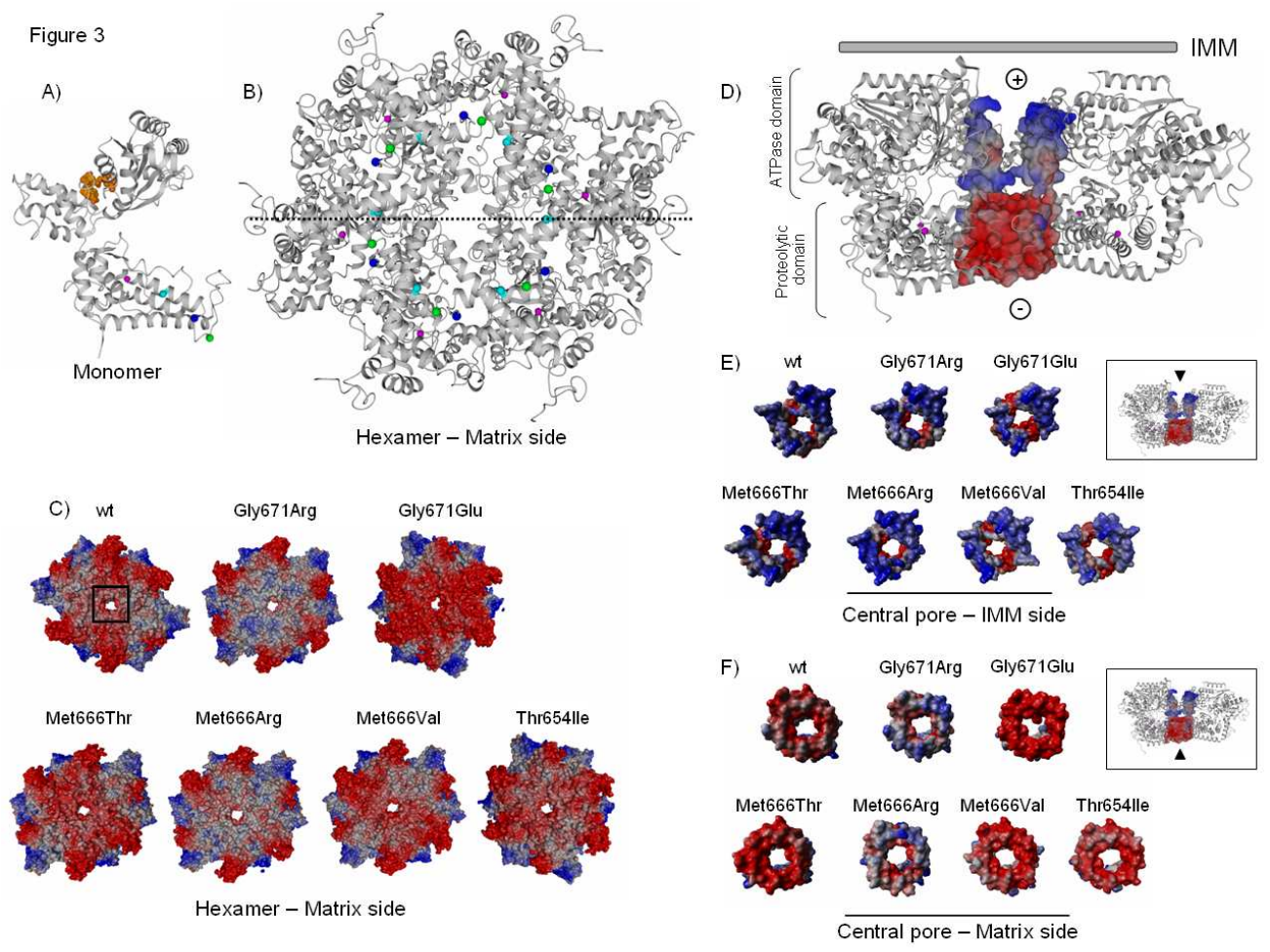

$451 \times 361 \mathrm{~mm}(72 \times 72 \mathrm{DPI})$

John Wiley \& Sons, Inc. 


\section{SUPPLEMENTARY MATERIALS AND METHODS.}

Mutation screening.

The 17 coding exons of the $A F G 3 L 2$ gene were PCR amplified in a total volume of $50 \mu 1$ using 30 ng of genomic DNA, $144 \mu \mathrm{M}$ dNTPs, $2 \mathrm{mM} \mathrm{MgCl}$, $1 \mathrm{U}$ of Taq Gold (Applied Biosystems, Foster City, CA, USA) and $200 \mathrm{nM}$ of forward and reverse primers reported in supplementary table S1. The amplification of exon 1 required a final concentration of $1 \mathrm{M}$ betaine (B0300, Sigma-Aldrich, St.Louis, MO, USA). Thermal cycling conditions were: $7 \mathrm{~min}$ at $95^{\circ} \mathrm{C}$, followed by 14 cycles of 30 sec at $95^{\circ} \mathrm{C}, 30 \mathrm{sec}$ at annealing temperature $(\mathrm{Ta})+7^{\circ} \mathrm{C}-0.5^{\circ} \mathrm{C} /$ cycle (see supplementary table 1 and $1 \mathrm{~min}$ at $72^{\circ} \mathrm{C}$; then 30 cycles consisting of $\mathrm{X} \mathrm{mn}$ at $95^{\circ} \mathrm{C}, 30 \mathrm{sec}$ at $\mathrm{Ta}$ (see supplementary table $\mathrm{S} 1$ ), and $1 \mathrm{~min}$ at $72^{\circ} \mathrm{C}$. A final step of 40 cycles consisting of $1 \mathrm{~min}$ at $98^{\circ} \mathrm{C}-1^{\circ} \mathrm{C} / \mathrm{cycle}$ was added in case of DHPLC analysis to increment heteroduplex formation.

The 17 coding exons of the SPG7 gene were amplified and directly sequenced. PCR was performed in a total volume of $25 \mu \mathrm{l}$, using $30 \mathrm{ng}$ of genomic DNA, $144 \mu \mathrm{M}$ dNTPs, $2.5 \mathrm{mM} \mathrm{MgCl} 2,0.5 \mathrm{U}$ of Taq Gold (Applied Biosystems) and $200 \mathrm{nM}$ of forward and reverse primers reported in supplementary table $\mathrm{S} 2$. The amplification of exon 1 required a final concentration of $1 \mathrm{M}$ betaine. Thermal cycling conditions for exons $1-13$ were: $7 \mathrm{~min}$ at $95^{\circ} \mathrm{C}$, followed by 14 cycles of $30 \mathrm{sec}$ at $95^{\circ} \mathrm{C}, 30 \mathrm{sec}$ at $\mathrm{Ta}+7^{\circ} \mathrm{C}-0.5^{\circ} \mathrm{C} /$ cycle (see supplementary table 2 and $1 \mathrm{~min}$ at $72^{\circ} \mathrm{C}$; then 30 cycles consisting in $\mathrm{X} \mathrm{mn}$ at $95^{\circ} \mathrm{C}, 30 \mathrm{sec}$ at $\mathrm{Ta}$, and $1 \mathrm{~min}$ at $72^{\circ} \mathrm{C}$; with a final extension for $10 \mathrm{~min}$ at $72^{\circ} \mathrm{C}$. Thermal cycling conditions for exons $14-17$ were: $7 \mathrm{~min}$ at $95^{\circ} \mathrm{C}, 30$ cycles at $95^{\circ} \mathrm{C}, 30 \mathrm{sec}$ at $\mathrm{Ta}$, and $1 \mathrm{~min}$ at $72^{\circ} \mathrm{C}$; final extension for $10 \mathrm{~min}$ at $72^{\circ} \mathrm{C}$. Fragments were purified using the ExoSAP method (MBI-Fermentas), and directly sequenced using the Big-Dye cycle sequencing kit and an ABI Prism 3100 Avant automatic sequencer (Applied Biosystems).

\section{Minigene assay.}

A minigene assay was set up to test the effect of $A F G 3 L 2$ c.293-13_293-14delTT sequence variant on splicing. We amplified a $327 \mathrm{bp}$ fragment from a subject carrying the variant. The forward 
primer (5'-ATGCGAATTCTTGTATTCTTTCTCATAGTGCTTCA) introduced a EcoRI restriction site, and the reverse primer (5'-TACGTCTAGAAATGCCTCCCAACCTTCTCT) introduced a $X b a \mathrm{I}$ restriction site. The fragment was sequenced to exclude the presence of PCRintroduced mutations. The PCR product was cloned into a pTZ57R/T vector using the InsTA Cloning kit (Invitrogen), and transformed in DH5 $\alpha$ bacterial cells following manufacturer's recommendations (RBC Bioscience, Chung Ho City, Taiwan). Plasmids were extracted using standard methods, checked by sequencing, and digested with EcoRI and XbaI restriction endonucleases. The insert was gel-purified and sub-cloned into a pAltermax modified vector (kindly provided by dr. Gareth Eldvige, Wellcome Trust Centre, Oxford, UK, and dr. Ivana Kurelac, University of Bologna). Plasmids containing the wild-type or the variant sequence were used to transform HEK293 cells using the TurboFect kit (Fermentas). After 48h, RNA was extracted with the RNeasy Kit (Qiagen), retrotranscribed with the GoScript kit (Promega). The cDNA was amplified and sequenced with vector primers. 
Supp. Table S1. Primers, PCR and DHPLC conditions for AFG3L2 mutation screening

\begin{tabular}{|c|c|c|c|}
\hline Exon & Primers (Forward/Reverse) & PCR Ta $\left({ }^{\circ} \mathbf{C}\right)$ & DHPLC Tm $\left({ }^{\circ} \mathrm{C}\right)^{1}$ \\
\hline 1 & $\begin{array}{l}\text { 5'-GTTGAGAGCTTGGGCTCCTCCGTGA } \\
\text { 5'-CCAGTGACCTTGACGTCCGCTCTCC }\end{array}$ & 69 & $68 / 69 / 69.8$ \\
\hline 2 & $\begin{array}{l}\text { 5'-TTATGACCAGGAAATGAAGC } \\
\text { 5'-GGTTGGGTCTTTTGTCTCCTT }\end{array}$ & 59 & $52.3 / 57.3$ \\
\hline 3 & $\begin{array}{l}\text { 5'-GATGCATCAGCTGCTTTGAA } \\
\text { 5'-GGTAGTTTCCACTGAACAAAG }\end{array}$ & 55 & 53.8 \\
\hline 4 & $\begin{array}{l}\text { 5'-GCTGAGAGAGCTAAAACCTTGC } \\
\text { 5'-AGAGAAGGTTGGGAGGCATT }\end{array}$ & 55 & $58.5 / 60.0 / 62.0$ \\
\hline 5 & $\begin{array}{l}\text { 5'-AGAGAAGGTTGGGAGGCATT } \\
\text { 5'-ACCAAAGAAGTGACAGTCAGC }\end{array}$ & 55 & $56.0 / 58.0 / 60.0$ \\
\hline 6 & $\begin{array}{l}\text { 5'-TGAGCTTAAAAGAGTATCTCAAGTATTTT } \\
\text { 5'-TGAGGCAGGTTTTCCTTTCA }\end{array}$ & 56 & $52.4 / 53.4 / 57.0 / 58.8$ \\
\hline 7 & $\begin{array}{l}\text { 5'-TTGAACCGTTTAGTGAATTGAACC } \\
\text { 5'-GAACCACAGGCAGCACAGTC }\end{array}$ & 56 & $53.3 / 55.7 / 58.1$ \\
\hline 8 & $\begin{array}{l}\text { 5'-GAAAGCTGGAGGTGAGCAG } \\
\text { 5'-GAGGATCGTTTTGGGTCA }\end{array}$ & 55 & $55.5 / 57.5 / 61.8$ \\
\hline 9 & $\begin{array}{l}\text { 5'-TGTGGATACACAATTTACTTTTCTGGA } \\
\text { 5'-GTGCCTCCATCTGTGGTGAA }\end{array}$ & 56 & $52.2 / 69.4 / 62.0$ \\
\hline 10 & $\begin{array}{l}\text { 5'-CCGATTTATTTCATTTCTTATTCAGAG } \\
\text { 5'-GCCTGGACGACAGAGTCA }\end{array}$ & 56 & $56.4 / 58.0 / 60.8$ \\
\hline 11 & $\begin{array}{l}\text { 5'-GCTATGAATTTGCAGTGCTC } \\
\text { 5'-AGGTCCAGTGCTCATGAGTG }\end{array}$ & 57 & n.a. ${ }^{2}$ \\
\hline 12 & $\begin{array}{l}\text { 5'-AGGTCCAGTGCTCATGAGTG } \\
\text { 5'-TTCTTTACTGTGGGCTTCCT }\end{array}$ & 57 & $55.6 / 57.6$ \\
\hline 13 & $\begin{array}{l}\text { 5'-GATCAGTTTGGGCGTATTTCG } \\
\text { 5'-AATCCCTGGCCTCAAATTCA }\end{array}$ & 56 & $55.5 / 57.5 / 58.4$ \\
\hline 14 & $\begin{array}{l}\text { 5'-TTGTGATAGGCAGCTCAGTC } \\
\text { 5'-CAAGCTACACTCCTGCAAAG }\end{array}$ & 57 & $56.8 / 61.5 / 63.0$ \\
\hline 15 & $\begin{array}{l}\text { 5'-GTCTTCATCTGTAGTAGGATCTTCAA } \\
\text { 5'-CGTGCAAATATGAATACATGAGG }\end{array}$ & 56 & $55.8 / 56.8$ \\
\hline 16 & $\begin{array}{l}\text { 5'-GATTTTGTCTGGTTAAAGAACAATCA } \\
\text { 5'-CCAACCAAAACAGTCTATCTATCACTTC }\end{array}$ & 56 & $53.0 / 56.1 / 57.8$ \\
\hline 17 & $\begin{array}{l}\text { 5'-GACTTTGCTGAGTAACTGTATTTAATG } \\
\text { 5'-ATGCACCAGCTGAAACCACA }\end{array}$ & 56 & $53.6 / 57.2 / 60.5$ \\
\hline
\end{tabular}

Notes: n.a.: not applicable; ${ }^{1}$ as determined by DHPLC Melt software; ${ }^{2} A F G 3 L 2$ exon 11 was directly sequenced in all subjects. Ta=annealing temperature; $A F G 3 L 2$ RefSeq NM_006796.1 
Supp. Table S2. Primers and PCR conditions for SPG7 mutation screening. $\mathrm{Ta}=$ annealing temperature

\begin{tabular}{|c|c|c|}
\hline Exon & Primers (Forward/Reverse) & Ta $\left({ }^{\circ} \mathbf{C}\right)$ \\
\hline 1 & $\begin{array}{l}\text { 5'-CGCAGGCGCCACGTCAGA } \\
\text { 5'-GCCGGGCTGGGCCTTACAGA }\end{array}$ & 63 \\
\hline 2 & $\begin{array}{l}\text { 5'-TGTTACCTAAAGCTTTGACCTATTGC } \\
\text { 5'-GCTCTGATCACACCATTGTACTGC }\end{array}$ & 58 \\
\hline 3 & $\begin{array}{l}\text { 5'-ACACTGTTGTCCTGTATGCCTCC } \\
\text { 5'-TCCAGACTGGTTTCACCTTGCTA }\end{array}$ & 58 \\
\hline 4 & $\begin{array}{l}\text { 5'-GATGTCGCCCGTGTCTGTTG } \\
\text { 5'-CCACAGCCTCACTCTCACAGG }\end{array}$ & 58 \\
\hline 5 & $\begin{array}{l}\text { 5'-GGCTCTCTGTTGACTGTAGGGTTG } \\
\text { 5'-TCTGTTTCTCAGATTACAAAGCCAA }\end{array}$ & 58 \\
\hline 6 & $\begin{array}{l}\text { 5'-CGTAGGGATTCCTCGTCTCATCT } \\
\text { 5'-TTCAGGCTACTCTCTGCAACAGG }\end{array}$ & 58 \\
\hline 7 & $\begin{array}{l}\text { 5'-GCATCGTGCTGCTGATTTCC } \\
\text { 5'-GAGCCCTTCTGGGAGAGGAG }\end{array}$ & 58 \\
\hline 8 & $\begin{array}{l}\text { 5'-CGTGACCCAGAGAGACCTTACCT } \\
\text { 5'-ACACCAGAGGAAGGATGTGTGAA }\end{array}$ & 58 \\
\hline 9 & $\begin{array}{l}\text { 5'-GGGTACAGGAAGAGGCTTTGTTT } \\
\text { 5'-CAACCTGTTCTGAAAGACATCGG }\end{array}$ & 58 \\
\hline 10 & $\begin{array}{l}\text { 5'-CTCTCTCCCTCCTGTGTCCTG } \\
\text { 5'-GGCTTCACACCAAGAAGTGTCTTA }\end{array}$ & 58 \\
\hline 11 & $\begin{array}{l}\text { 5'-CGCACCTGTGGCAGTAACTA } \\
\text { 5'-AGGCCTCGATGCTGTTTG }\end{array}$ & 56 \\
\hline 12 & $\begin{array}{l}\text { 5'-TCCTCCTCTTAAGCCCTGATAGC } \\
\text { 5'-TCAATACCTGCCTGGGTATTTCT }\end{array}$ & 58 \\
\hline 13 & $\begin{array}{l}\text { 5'-CTGGTCTCGAACTCCTGTCCTCAG } \\
\text { 5'-AGGCTTTCCTCTCACATGACCTACA }\end{array}$ & 63 \\
\hline 14 & $\begin{array}{l}\text { 5'-GCATCCTGCCTACTGACCTG } \\
\text { 5'-GAAAAGCGCTCTGAAACCTC }\end{array}$ & 59 \\
\hline 15 & $\begin{array}{l}\text { 5'-TGCTGAGGATGCCTCTGTCT } \\
\text { 5'-GCGACCCTTGTGTGGTAGA }\end{array}$ & 59 \\
\hline 16 & $\begin{array}{l}\text { 5'-GTGTTCCCAGTCTGCCATTTC } \\
\text { 5'-TGTGTGGACACTGTGTGACG }\end{array}$ & 59 \\
\hline 17 & $\begin{array}{l}\text { 5'-CCTGGGGACTCACACACTG } \\
\text { 5'-CCTCACTTCCCGGACCAC }\end{array}$ & 59 \\
\hline
\end{tabular}

SPG7 RefSeq NM_003119.2 


\section{Bioinformatics analysis.}

To build a three dimensional model of the C-terminal region of AFG3L2, the sequence corresponding to residues 306-762 was submitted to PDB-blast

(http://protein.cribi.unipd.it/pdbblast/) that recognized the cell division bacterial protein FtsH with an R-score of 1E-117. Its crystal structure was present in the protein database (PDB) as 2CE7, which contains the AAA domain and a protease domain. Crystallization experiments of 2CE7 gave rise to a tetragonal crystal form containing six monomers per asymmetric unit. These belong to two virtually identical half-hexamers; the complete hexameric molecules are generated by a crystallographic two-fold axis.

The AAA ring does not form a regular hexagon and the contacts of one AAA domain with the two other interacting domains in the ring are much more asymmetric than those observed in the protease domain.

As a result, three different monomer conformations are present in 2CE7 structure.

In order to build the AFG3L2 hexamer model, we constructed, three different models based on the conformations of the three monomers present in 2CE7 structure, using the program NEST (http://trantor.bioc.columbia.edu/programs/jackal/index.html). Subsequently to obtain the hexamer model we superimposed them to the corresponding 2CE7 monomers in its hexamer using the program SHEBA (Jung and Lee, 2000). Upon superimposition, the ADP molecule and the Mg2+ and $\mathrm{Zn} 2+$ ions were added to the model.

Using the program Yasara (www.yasara.org), we introduced the Thr654Ile, Met666Thr, Met666Arg, Met666Val, Gly671Glu and Gly671Arg mutations. Next we refined the model using the program Yasara with the protocol described below.

Each model was refined performing a 150 ps simulation of the homology models using the protocol described in (Krieger, et al., 2004). It saves one PDB file every 25 picoseconds, and allows the user to identify the best snapshot giving as output a table with force field energies, PhiPsi, Backbone and Packing3 WHATIF checks (Vriend, 1990). 
In order to choose the best conformer saved during the refinement procedure we derived a quality parameter defined as follows:

$\mathrm{Q}=($ Energy/10000) $-($ PhiPsi+Backbone+Packing3) $=$ quality

The conformer having the lowest value of $\mathrm{Q}$ was selected for subsequent analyses.

Data on the electric dipole moment calculated using the Yasara software. The difference of electrostatic potential $(\mathrm{mV})$ was calculated from the measure of the electric dipole moment using the formula: $\Delta V=\frac{d}{\left(4 \pi \cdot r^{2} \cdot \varepsilon_{0}\right)} \cdot \mathrm{D}=$ electric dipole moment; $\mathrm{r}=$ distance between examer surfaces; $\varepsilon 0=$ electric constant in vacuum.

The $\mathrm{pH}$ of the AFG3L2 hexamer catalitic site was calculated using $\mathrm{pH}$ Calculator software (http://www.webqc.org/phsolver.php). pKa values were obtained from the PROPKA software ver 2.0 (Guerois, et al., 2002). We calculated the $\mathrm{pH}$ of normal hexamer and hexamers containing identified mutations for all aminoacids distant $<0.5 \mathrm{~nm}$ from the $\mathrm{Zn}$ atom within the catalytic site (constant arbitrary concentration set at $0.01 \mathrm{M}$ ).

The energetic stability of AFG3L2 protein and the interaction energy of each monomer were calculated using the FoldX software ver 3.0 (Guerois, et al., 2002). We calculated both the interaction energy between one monomer and the two flanking monomers, and between one monomer and the remaining hexamer.

To verify the possible three-dimensional structure of AFG3L2 homopolymer or heteropolymer, a 3D model of the C-terminal tract of SPG7, a known interactor of AFG3L2 (Atorino, et al., 2003) was also created following the same protocol as above.

Homo- and Heteropolymers were reconstructed with the software NEST and SHEBA (Jung and Lee, 2000; Petrey, et al., 2003).

Finally, the software PoPMuSic estimated the stabilizing/destabilizing effect of each aminoacidic substitution, through the measurement of the free energy difference $(\Delta \Delta \mathrm{G})$ of the molecule (Gilis and Rooman, 2000). 
Supp. Table S3. AFG3L2 variants found in 366 ADCA patients.

\begin{tabular}{|c|c|c|c|c|}
\hline Variants & $\begin{array}{l}\text { Exon / } \\
\text { Intron } \\
\end{array}$ & Patients & Controls & Notes \\
\hline rs12327346:C>G & EX1 & $20 / 366$ & $7 / 95$ & \\
\hline c.-92T $>\mathrm{C}$ & & $1 / 366$ & $0 / 95$ & \\
\hline c. $-71 \mathrm{C}>\mathrm{T}$ & & $4 / 366$ & $1 / 95$ & \\
\hline c. $-48 G>A$ & & $2 / 366$ & $0 / 95$ & \\
\hline c. $-32 \mathrm{C}>\mathrm{T}$ & & $1 / 366$ & $0 / 95$ & \\
\hline c.293-33G $>A$ & IVS3 & $1 / 366$ & $0 / 95$ & The variant does not alter splicing \\
\hline c.293-13_293-14delTT & & $2 / 366$ & $0 / 95$ & The variant does not alter splicing ${ }^{1}$ \\
\hline c. $400-14 C>G$ & IVS4 & $4 / 366^{2}$ & $0 / 95$ & The variant does not alter splicing \\
\hline c. $718 C>A(p .=)$ & EX7 & $1 / 366$ & n.a. & The variant does not alter splicing \\
\hline rs8097342:G>A & IVS7 & $120 / 366$ & n.a. & \\
\hline rs8091858:C>T & IVS8 & $27 / 366$ & $0 / 95$ & \\
\hline c.1027-12T >C & & 2/366 & $0 / 95^{3}$ & The variant does not alter splicing \\
\hline rs9966470:A>T & IVS9 & $85 / 366$ & $21 / 95$ & \\
\hline c. $1165-24 \mathrm{G}>\mathrm{A}$ & & $5 / 366$ & $1 / 95$ & \\
\hline c.1319-59G $>$ T & IVS10 & $3 / 366$ & $0 / 95$ & The variants does not alter splicing \\
\hline c.1319-40C >T & & 1/366 & $0 / 95$ & The variants does not alter splicing \\
\hline rs11080572:G>A & EX11 & $349 / 366^{4}$ & $85 / 95^{5}$ & \\
\hline c.1426+21_1426+22insCAGGTC & IVS11 & $1 / 366$ & $0 / 95$ & The variant does not alter splicing \\
\hline c. $1479 \mathrm{G}>\mathrm{A}(\mathrm{p} .=)$ & EX12 & $1 / 366$ & $0 / 95$ & The variant does not alter splicing \\
\hline rs11553521:A>G & EX13 & $125 / 366$ & $26 / 95$ & \\
\hline c. $1664-39 G>A$ & IVS13 & $8 / 366$ & $2 / 95$ & \\
\hline c.1664-9T>C & & $1 / 366$ & $0 / 95$ & The variant does not alter splicing \\
\hline c. $2175+18 \mathrm{G}>\mathrm{A}$ & IVS16 & $9 / 366$ & $4 / 190^{6}$ & \\
\hline rs1129115:G>C & EX17 & $117 / 366$ & $26 / 95$ & \\
\hline c. $2325 \mathrm{C}>\mathrm{T}(\mathrm{p} .=)$ & & $1 / 293$ & $0 / 95$ & Not found in an affected niece \\
\hline
\end{tabular}

In bold, variants not found among controls and/or in the dbSNP(129). Controls were all of French origin, except for note 3 95 Italian controls, and note 6 - 95 Italian and 95 French controls; 1-The effect on splicing was tested using a minigene assay (see Supp. Materials and Methods); 2-The c.400-14C >G variant was tested in one family and did not segregate from the affected father to the affected son; 4-Two hundred-24 cases were homozygous (A/A) and 125 heterozygous (G/A); n.a. $=$ not available; 5-Fifty-seven controls were homozygous (A/A) and 28 heterozygous (G/A). 
Supp. Table S4. Mutation effect on the electric dipole of the translocation channel and on the potential difference between the inner mitochondrial membrane side and the matrix side of the hexamer.

\begin{tabular}{ccccc}
\hline & $\begin{array}{c}\text { Potential difference }-\boldsymbol{P D} \\
(\mathbf{m} \boldsymbol{V})\end{array}$ & $\begin{array}{c}\text { PD compared to wild } \\
\text { type }(\boldsymbol{m} \boldsymbol{V})\end{array}$ & $\begin{array}{c}\text { PD compared to wild } \\
\text { type }(\%)\end{array}$ & $\begin{array}{c}\text { Electric dipole } \\
(\boldsymbol{C} \boldsymbol{m})\end{array}$ \\
\cline { 2 - 5 } wt & 22,274 & & & $1,79 * 10^{-26}$ \\
T654I & 22,60 & 0,33 & $1,48 \%$ & $1,82 * 10^{-26}$ \\
M666V & 22,305 & 0,031 & $0,14 \%$ & $1,79 * 10^{-26}$ \\
M666T & 22,945 & 0,671 & $3,01 \%$ & $1,85 * 10^{-26}$ \\
M666R & 19,548 & $-2,726$ & $-12,24 \%$ & $1,57 * 10^{-26}$ \\
G671E & 25,736 & 3,462 & $15,54 \%$ & $2,07 * 10^{-26}$ \\
G671R & 18,887 & $-3,387$ & $-15,21 \%$ & $1,52 * 10^{-26}$ \\
\hline
\end{tabular}

Yellow $=$ wild-type $(\mathrm{wt})$ values; Green $=$ lower dipole and potential difference; Blue $=$ dipole and potential difference not significantly different from the wild-type; Red = higher dipole and potential difference. $\mathrm{mV}=$ millivolts; $\mathrm{C} \mathrm{m}=$ Coulomb meter.

Supp. Table S5. Mean interaction energy ${ }^{\S}(\mathrm{Kcal} / \mathrm{Mol})$ between each monomer of the AAAprotease (A to $\mathrm{F}$ ) and the other five monomers

\begin{tabular}{cccccccc}
\hline & \multicolumn{7}{c}{ Monomer } \\
\hline wt & A & B & C & D & E & F & Mean $^{1}$ \\
\cline { 2 - 8 } T654I & -49.89 & -79.31 & -57.50 & -59.64 & -82.24 & -54.58 & -63.86 \\
M666V & -43.23 & -76.66 & -66.77 & -55.32 & -76.86 & -57.56 & -62.73 \\
M666T & -56.73 & -83.46 & -51.03 & -37.19 & -60.82 & -56.99 & -57.70 \\
M666R & -50.50 & -64.60 & -46.42 & -48.36 & -76.81 & -58.26 & -57.49 \\
G671E & -35.73 & -71.15 & -49.36 & -37.83 & -58.24 & -42.46 & -49.13 \\
G671R & -51.46 & -79.02 & -54.77 & -61.61 & -77.72 & -50.24 & -62.13 \\
\hline
\end{tabular}

${ }^{1}$ Yellow $=$ wild-type $(\mathrm{wt})$ interaction; Green = lower interaction; Blue = slightly lower interaction

${ }^{\S}$ Interaction energy was calculated using the application FoldX ver3.0 (Guerois R et al., 2002) 